\title{
ECM1 promotes migration and invasion of hepatocellular carcinoma by inducing epithelial-mesenchymal transition
}

\author{
Hao Chen, Weidong Jia and Jiansheng Li*
}

\begin{abstract}
Background: Extracellular matrix protein 1 (ECM1) is a glycoprotein involved in many biologic processes. To determine the expression of ECM1 in hepatocellular carcinoma (HCC), and to study the role of ECM1 in inducing epithelia-mesenchymal transition (EMT) to analyze the effect of ECM1 on the migration and invasion of HCC cells.

Methods: The expression of ECM1 in HCC specimens was examined by immunohistochemistry staining, and the correlations were analyzed between the expression of ECM1 and the clinicopathological data. The ECM1 expression plasmid was transfected into Bel-7402 cells to induce exogenous overexpression of ECM1 protein. The changes of the expression of ECM1, EMT-related protein (E-cadherin, Vimentin), in Bel-7402 cells were detected by Western blot after transfection of ECM1; the wound healing and invasion assay in vitro were used to determine the role of ECM1 gene transfection on the ability of migration and invasive potential of Bel-7402 cells.
\end{abstract}

Results: Immumohistochemistry staining method displayed the ECM1 expression was positively associated with vascular invasion, TNM stage, and poor prognosis. A significant positive correlation was found between the expressions of ECM1 and Vimentin. After ECM1 overexpression, Western blot exhibited that the expression of E-cadherin was down-regulated and Vimentin expression was up-regulated in Bel-7402 cells; the wound healing and invasion assay showed that the migration and invasion potentials of Bel-7402 cells were significantly enhanced.

Conclusions: ECM1, which displayed a high expression in HCC specimens, was closely associated with clinicopathologic data and may promote migration and invasion of HCC cells by inducing EMT.

Keywords: Extracellular matrix protein 1, Epithelia-mesenchymal transition, Hepatocellular carcinoma, Migration, Invasion

\section{Background}

Hepatocellular carcinoma (HCC) is the sixth most common malignancy and the third leading cause of cancerrelated death in the world with about 600 thousands deaths each year [1]. Till now, curative surgical resection of HCC remains the most effective therapy. Because of high rate of metastasis and recurrence after surgery, the prognosis of HCC remains dismal with $25-39 \%$ survival of patients in 5 years [2]. Therefore, better understandings of the molecular mechanisms that contribute to HCC invasion and metastasis are critically needed.

\footnotetext{
*Correspondence: lijiansheng1953@163.com

Department of Hepatic Surgery, Affiliated Provincial Hospital, Anhui Medical University, Anhui Province Key Laboratory of Hepatopancreatobiliary Surgery, 17 Lujiang Road, Hefei 230001, Anhui Province, People's Republic of China
}

Some phenotypic changes and molecular events are involved in cancer cell disintegration and migration into distant organs or tissues. The epithelial-to-mesenchymal transition (EMT), which is characterized by the downregulation or loss of epithelial markers (E-cadherin) and up-regulation of mesenchymal markers (Vimentin), is a crucial step in tumor invasion and metastasis [3-5].

Extracellular matrix protein 1 (ECM1), originally identified in 1994 as an $85 \mathrm{kDa}$ glycoprotein was secreted from osteogenic mouse stromal cell line MN7 that is established from the bone marrow stroma of an adult mouse [6, 7]. Presently, a number of studies have indicated that ECM1 is involved in various biological processes, such as mineralization, cell proliferation, angiogenesis, and skin diseases [8-15]. In most cancers, ECM1 was 
found to promote cancer progression and invasion, and overexpression of ECM1 has been identified as an indicator of poor prognosis [10,16-22]. Nevertheless, there are few previous studies on the role of ECM1 in HCC and EMT.

The current study is designed to evaluate the role of ECM1 expression in HCC and to elucidate the association with clinicopathological characteristics and prognosis of HCC. First, the expression of ECM1 in HCC tissues was detected using immunohistochemistry in a hospital-based cohort of patients. Next, we used the ECM1 expression plasmid transfect into Bel-7402 cells, to explore the association of ECM1 expression among E-cadherin and Vimentin.

\section{Methods}

\section{Patients and tissue samples}

One hundred and twenty patients with $\mathrm{HCC}$ who underwent curative surgical resection between 2008 and 2012 at the Provincial Hospital of Anhui Medical University were included. No patient received adjuvant therapy before surgery. These patients comprised of 93 males and 27 females, with mean age of 50.2 years (range: $21-73$ years). All included patients were staged according to the sixth edition of the tumor-node-metastasis (TNM) classification of the International Union against Cancer. Tumor differentiation was defined according to the Edmondson grading system. All tissue diagnoses were confirmed by permanent histology. Seventeen samples of normal liver tissues were acquired surgically from the patients who had received an operation due to liver trauma. The institutional Ethics Committee of AnHui Provincial Hospital approval for the project was achieved before the initiation of the study. Informed consent was obtained from each patient, and the study was in compliance with the Helsinki Declaration. These patients comprised of 11 males and 6 females, with mean age of 52 years (range: 19-70 years). The clinical characteristics of these patients have no significant difference between tumor patients.

The complete follow-up data were obtained from all patients. The patients were followed up until January 1, 2015. The mean follow-up was 28.4 months (range, 3-71 months). All patients were prospectively monitored using $\alpha$-fetoprotein (AFP), abdominal ultrasonography, and chest X-ray every 3-6 months after surgery. Computed tomography and/or magnetic resonance imaging were used if necessary. The overall survival (OS) was defined as the interval between the surgery and the death of patients or the last follow-up. The data were censored at the last follow-up for living patients. Disease-free survival (DFS) was measured from the date of surgery to the HCC recurrence or the last follow-up. In the DFS analysis, the data were censored for patients without tumor recurrence (Additional file 1).

\section{Cells and cell culture}

The hepatocellular carcinoma cell line Bel-7402 was purchased from the Liver Cancer Institute of Zhongshan Hospital, Shanghai, China. The cells were routinely grown as monolayers in Dulbecco's modified Eagle's medium (DMEM) (Gibco BRL, New York, NY, USA) with $10 \%$ (vol/vol) fetal bovine serum (Hyclone, Logan, UT, USA), $100 \mathrm{U} / \mathrm{ml}$ penicillin, and $100 \mathrm{U} / \mathrm{ml}$ streptomycin at $37^{\circ} \mathrm{C}$ in a humidified incubator containing $5 \% \mathrm{CO}_{2}$.

\section{Immunohistochemical staining reagents}

Rabbit anti-ECM1 antibody and mouse anti-Vimentin antibody were purchased from Proteintech Group Inc (USA). Horse-radish peroxidase-conjugated secondary antibody, phosphate-buffered saline (PBS), and 3,3-diaminobenzidine tetrahydrochloride (DAB) were obtained from Beijing Zhongshan Golden Bridge Biotechnology Company (China).

\section{Immunohistochemical staining and evaluation}

Tissue specimens were promptly fixed in $10 \%$ neutral formalin, embedded in paraffin, and cut into $3-\mu \mathrm{m}$ sections. Immunohistochemical staining was carried out following the manufacturer's instructions. Briefly, all sections were gradually deparaffinized with xylene and alcohol. The slides were processed with antigen retrieval by being boiled in citrate buffer ( $\mathrm{pH} \mathrm{6.0)}$ for $20 \mathrm{~min}$ and then cooled down at room temperature. Subsequently, the slides were incubated in a $10 \%$ hydrogen peroxide solution for $15 \mathrm{~min}$ to eliminate endogenous peroxidase activity. The sections were then immunostained with primary antibody of rabbit anti-ECM1 antibody (115211-AP, Proteintech Group, USA) and mouse anti-Vimentin antibody (ZM-0260, ZBGB-BIO) at $4{ }^{\circ} \mathrm{C}$ overnight. After rinsing with PBS for $5 \mathrm{~min}$, the sections were incubated in horse-radish peroxidase (HRP)-conjugated secondary antibody (PV-6000, ZSGB-BIO) for 20 min. Being washed again, peroxidase activity was visualized using freshly prepared DAB (ZLI-9017, ZBGB-BIO) and then counterstained lightly with Harris hematoxylin. The negative controls were processed in a similar manner with PBS instead of primary antibody.

ECM1 and Vimentin were mainly located in the cytoplasm of tumor cells. The intense of immunohistochemistry staining was quantified by the percentage of positive-staining cells. The positive-staining cell $<10 \%$ was clarified as negative (-), and $\geq 10 \%$ was positive $(+)$. Ten fields were selected, and expression in 1000 tumor cells (100 cells/field) was evaluated using a high power $(\times 400)$ of microscope. The immunohistochemical results were scored by three experienced pathologists, who were blinded to clinical data. 

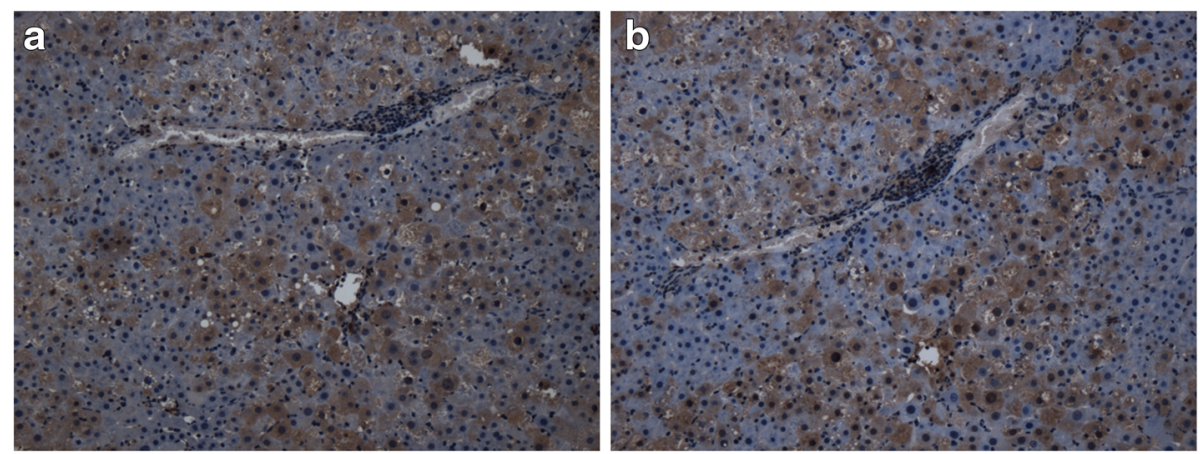

Fig. 1 a Positive immunostainings for ECM1 in HCC tissues. b Positive immunostainings for Vimentin in HCC tissues. Both ECM1 and Vimentin mainly expressed in the cytoplasm of HCC cells. Serial sections of tumor samples were made into $3-\mu m$ sections. Original magnification at $\times 200$

\section{Construction of ECM1 expression vector}

Taking the cDNA of human placenta tissue as the template, RT-PCR amplification was performed and then cloned into pEGFP-N2 vector. It was sequenced to obtain the complete coding sequence of ECM1. The pEGFP-N2 plasmid (Invitrogen) was connected with the fragments of target gene after the amplification of ECM1. The double endonuclease restriction of BamH I and Xho I was performed and purified, respectively. The plasmid and fragments of target gene were recovered, which were connected with T4 DNA ligase and then cultured in LB flat plate that contained the ampicillin. The positive clone was selected and sequenced to prove the successful construction of eukaryotic expression vector pEGFP-N2-ECM1.

\section{Western blotting assays}

Cultured cells in an exponentially growing phase and frozen tissue samples were extracted with $1 \mathrm{ml}$ of lysis buffer. The protein concentration of the lysate was determined by the BCA method (KeyGen, China). The extracts containing approximately $30 \mu \mathrm{g}$ of protein were loaded onto $10 \%$ sodium dodecyl sulfate polyacrylamide gel electrophoresis (SDS-PAGE), electrophoresed, and then transferred to polyvinylidence difluoride (PVDF) membranes (Immobilon-P. $0.45 \mu \mathrm{m}$, Millipore Corp., Bedford, MA, USA). The membranes were blocked with $5 \%$ skimmed milk in PBST (phosphate-buffered saline with $0.1 \%$ Tween 20) for $1 \mathrm{~h}$ and then incubated with primary antibody of rabbit anti-ECM1 antibody (Protein Group Inc, USA), rabbit anti-Vimentin antibody (ab92574, Abcam, USA), rabbit anti-E-cadherin antibody (ab15148, Abcam, USA), and rabbit anti- $\beta$-actin (ab133626, Abcam, USA) antibody at $4{ }^{\circ} \mathrm{C}$ overnight. After being washed three times with PBST buffer, the membranes were incubated with secondary peroxidase-conjugated antibody (ZB-2308, ZSGB-BIO) for $1 \mathrm{~h}$ at room temperature. After being washed three more times, the protein bands were detected by enhanced chemiluminescence (Pierce, Rockford, USA) according to the manufacturer's instruction. $\beta$-actin antibody was served as a control to confirm equal loading. Densitometry index analysis of the bands was made using gel imagery system.

\section{Cell migration and invasion assays}

Cell migration was assayed in a transwell chamber with 24-well, $8.0-\mathrm{mm}$ pore polycarbonate membrance (Corning, USA). The same membranes were precoated with matrigel (BD Biosciences, USA) for cell invasion assay. Briefly, $100 \mu \mathrm{l} 1 \mathrm{mg} / \mathrm{ml}$ matrigel solution was added to the upper chamber, and then plate was immediately inverted and gelled at $37{ }^{\circ} \mathrm{C}$ for $30 \mathrm{~min}$ in an incubator. After 72-h transfection, cells were digested and resuspended to a concentration of $1.0 \times 10^{5} / \mathrm{ml}$ using serum-free DMEM with $0.1 \%$ bovine serum albumin. Two hundred-milliliter cell suspensions were seeded in the upper chamber and filled the lower chamber with 500-ml complete DMEM. The chamber was rinsed in PBS $24 \mathrm{~h}$ after incubation and stained with $0.1 \%$ crystal violet for $15 \mathrm{~min}$. The cells were counted using a light microscope (magnification $\times 200$ ). Migrated cells were averaged from five fields per one chamber, and three chambers were used on one experiment (Additional file 2).

\section{Statistical analysis}

All statistical analyses were performed using the statistical package SPSS 13.0 (SPSS Inc., Chicago, IL). Fisher's exact test and the $\chi^{2}$ test were performed to assess associations between ECM1 expression and clinicopathological parameters. The Kaplan-Meier method was used for

Table 1 Expression of ECM1 in HCC and normal liver tissues

\begin{tabular}{|c|c|c|c|c|c|}
\hline & \multirow[t]{2}{*}{ Cases } & \multicolumn{4}{|c|}{ ECM1 } \\
\hline & & - & + & $x^{2}$ & $P$ \\
\hline $\mathrm{HCC}$ & 120 & 32 & 88 & 16.745 & $<0.001$ \\
\hline Normal & 17 & 13 & 4 & & \\
\hline
\end{tabular}

$P$ value was generated by comparing all subgroups and analyzed by the chi-square test. $P<0.05$ was considered as statistically significant 
Table 2 Correlation between the expression of ECM1 in 120 $\mathrm{HCC}$ tissues and their clinicopathological characteristics

\begin{tabular}{|c|c|c|c|c|c|}
\hline \multirow[t]{2}{*}{ Characteristics } & \multirow[t]{2}{*}{ Case } & \multicolumn{4}{|c|}{ ECM1 } \\
\hline & & - & + & $x^{2}$ & $P$ \\
\hline Age (year) & & & & 0.001 & 0.978 \\
\hline$\leq 50$ & 56 & 15 & 41 & & \\
\hline$>50$ & 64 & 17 & 47 & & \\
\hline Gender & & & & 0.156 & 0.692 \\
\hline Male & 93 & 24 & 69 & & \\
\hline Female & 27 & 8 & 19 & & \\
\hline Nodule & & & & 0.002 & 0.967 \\
\hline Single & 89 & 26 & 63 & & \\
\hline Multiple & 31 & 6 & 25 & & \\
\hline Tumor size $(\mathrm{cm})$ & & & & 0.477 & 0.490 \\
\hline$\leq 5$ & 65 & 19 & 46 & & \\
\hline$>5$ & 55 & 13 & 42 & & \\
\hline $\operatorname{AFP}(\mathrm{ng} / \mathrm{ml})$ & & & & 0.477 & 0.490 \\
\hline$\leq 400$ & 55 & 13 & 42 & & \\
\hline$>400$ & 65 & 19 & 46 & & \\
\hline Tumor capsule & & & & 0.441 & 0.507 \\
\hline Well & 66 & 16 & 50 & & \\
\hline Poorly & 54 & 16 & 38 & & \\
\hline Edmondson's grade & & & & 2.965 & 0.085 \\
\hline$|/| \mid$ & 52 & 18 & 34 & & \\
\hline III/IV & 68 & 14 & 54 & & \\
\hline $\mathrm{HBsAg}$ & & & & 1.108 & 0.293 \\
\hline Positive & 104 & 26 & 78 & & \\
\hline Negative & 16 & 6 & 10 & & \\
\hline Child-Pugh class & & & & 0.010 & 0.921 \\
\hline A & 93 & 25 & 68 & & \\
\hline B & 27 & 7 & 20 & & \\
\hline Vascular invasion & & & & 4.733 & 0.030 \\
\hline Absent & 83 & 27 & 56 & & \\
\hline Present & 37 & 5 & 32 & & \\
\hline Liver cirrhosis & & & & 2.472 & 0.291 \\
\hline Without/mild & 67 & 21 & 46 & & \\
\hline Moderate & 38 & 9 & 29 & & \\
\hline Severe & 15 & 2 & 13 & & \\
\hline TNM stage & & & & 6.028 & 0.049 \\
\hline 1 & 64 & 23 & 41 & & \\
\hline$\|$ & 31 & 5 & 26 & & \\
\hline$\|$ & 25 & 4 & 21 & & \\
\hline
\end{tabular}

$P$ value was generated by comparing all subgroups and analyzed by the chi-square test. $P<0.05$ was considered as statistically significant

survival analysis, and differences in survival were estimated using the log-rank test. A multivariate survival analysis was performed for all parameters that were significant in the univariate analyses using the Cox regression model. The correlation between ECM1 and Vimentin was determined using Spearman rank correlation coefficient. The difference of ECM1 protein expression levels among cell lines was examined by using Student $t$ test. A $P$ value $<0.05$ was considered statistically significant.

\section{Results}

Immunohistochemical expression of ECM1 in HCC and normal liver tissues

Immunohistochemical analysis revealed that both ECM1 staining was found in the cytoplasm (Fig. 1). ECM1 was detected in $73.3 \%(88 / 120)$ of HCC tissues, while $23.5 \%$ $(4 / 17)$ in the normal liver tissues, respectively. The expression of ECM1 in HCC tissues was significantly higher than that in normal liver tissues $(P<0.01)$ (Table 1$)$.

We evaluated the association between ECM1 expression and clinicopathological characteristics, including age, gender, tumor size, number of tumor nodules, tumor capsule, HBsAg status, serum AFP level, Edmondson's grade, vascular invasion, Child-Pugh class, stage of liver cirrhosis, and TNM stage. ECM1 was significantly associated with TNM stage $(P=0.049)$ and venous invasion $(P=0.030)$. The expression of ECM1 was not associated with gender, age, HBsAg status, Child-Pugh class, tumor capsule, and AFP level (Table 2).

\section{Correlation with ECM1 and Vimentin expression in HCC}

Vimentin is an important hallmark of EMT, and high expression of Vimentin was also observed mainly in the cytoplasmic staining. ECM1 and Vimentin expression was positive in $88(73.3 \%)$ and $71(59.1 \%)$ cases, respectively. Additionally, ECM and Vimentin were co-positive in 66 $(55.0 \%)$ cases. Using the Spearman rank test, the immunostaining expression of ECM1 was positively correlated with Vimentin expression in the HCC tissues $(r=0.534, P<0.001)$ (Table 3$)$.

\section{The impact of ECM1 expression on HCC prognosis}

As was shown in Fig. 2, ECM1 was significantly associated with poor OS and DFS of HCC obtained by the Kaplan-Meier method using the log-rank test. In addition,

Table 3 The correlation between ECM1 and Vimentin expression in HCC tissues

\begin{tabular}{llllll}
\hline Vimentin & ECM1 & & $r_{\mathrm{s}}$ & $P$ \\
\cline { 2 - 3 } & Negative & Positive & & \\
\hline Negative & 27 & 22 & 0.534 & $<0.001$ \\
Positive & 5 & 66 & & \\
\hline
\end{tabular}

$P$ value was generated by determined using the Spearman rank correlation coefficient. $P<0.05$ was considered as statistically significant 

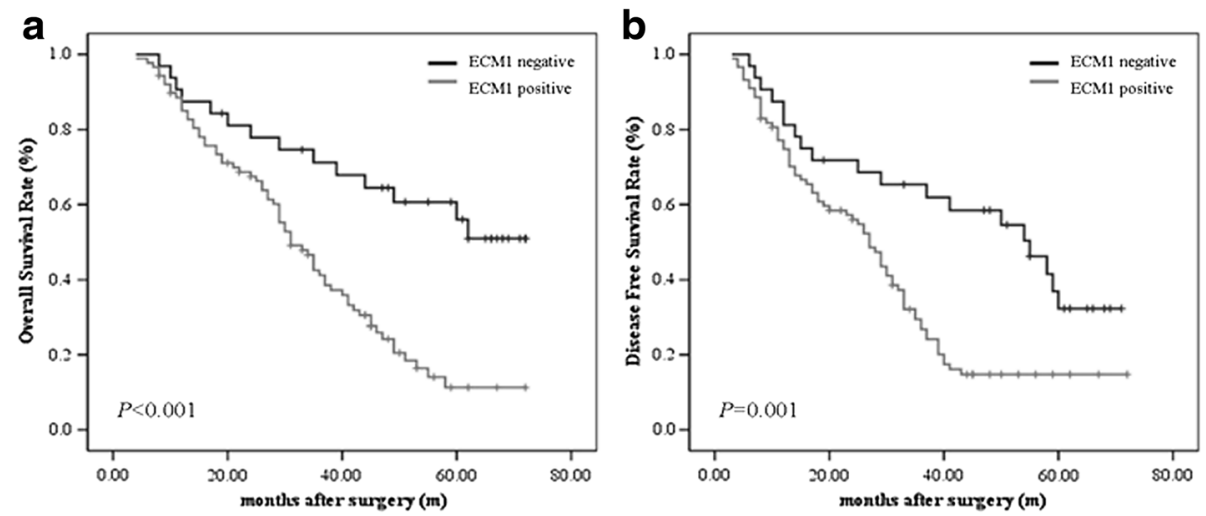

Fig. 2 a Kaplan-Meier analysis of overall survival curve of HCC patients according to ECM1 expression. The HCC patients with ECM1-positive showed significantly shorter overall survival survival rates than those with ECM1-negative. b Kaplan-Meier analysis of disease-free survival curve of HCC patients according to ECM1 expression. The expression of ECM1 is associated with decreased disease-free survival rate

the survival benefits were also found in patients with earlier TNM stage, absence of vascular invasion, single nodule, smaller tumor size, well differentiation, intact tumor capsule, and mild liver cirrhosis; in contrast, other parameters did not predict HCC prognosis (Table 4). Multivariate survival analysis enrolled above mentioned significant parameters and was performed using Cox regression. Results revealed that ECM1 expression, tumor size, number of tumor nodules, tumor capsule, vascular invasion, and liver cirrhosis were the independent prognostic factors for both OS and DFS in HCC patients after curative resection $(P<0.05)$ (Table 5$)$.

\section{Effect of ECM1 on expression of E-cadherin and Vimentin protein in $\mathrm{HCC}$ cells}

The ECM1 level of Bel-7402 cells was significantly increased detected by immunohistochemical staining (Fig. 3).
As shown in Fig. 4, the increased expression of ECM1 could lead to the up-regulated expression of Vimentin protein and down-regulated expression of E-cadherin protein in Bel-7402 cells. The relative quantity of three protein expressed levels in cells with significant difference (ECM1: $t=12.909, P<0.01$; Vimentin; $t=10.564, P<0.01$; E-cadherin: $t=-8.558, P=0.002$ ).

\section{ECM1 overexpression induces cell migration and invasion}

To evaluate the role of ECM1 in the regulation of HCC cells migration, we carried out a wound healing assay at $24 \mathrm{~h}$ post-infection. The wound healing assay revealed that the migration rates of the cells in the Bel-7402 group infected with pEGFP-N2-ECM1 were significantly increased compared with those without transfected group ( $F=110.592, P<0.01$ (Fig. 5). Subsequently, we assessed the effect of ECM1 on cell invasion with a transwell assay.

Table 4 Univariate survival analysis of OS and DFS in 120 patients with HCC

\begin{tabular}{|c|c|c|c|c|c|c|}
\hline \multirow[t]{2}{*}{ Characteristics } & \multicolumn{3}{|l|}{ OS } & \multicolumn{3}{|l|}{ DFS } \\
\hline & $\mathrm{HR}$ & $95 \% \mathrm{Cl}$ & $P$ & $\mathrm{HR}$ & $95 \% \mathrm{Cl}$ & $P$ \\
\hline Age (>50 vs $\leq 50$ years) & 1.397 & $0.898-2.175$ & 0.138 & 1.418 & $0.931-2.161$ & 0.104 \\
\hline Gender (male vs female) & 0.737 & $0.414-1.311$ & 0.299 & 0.874 & $0.521-1.466$ & 0.610 \\
\hline Nodule (multiple vs single) & 3.254 & $2.005-5.280$ & $<0.001$ & 3.204 & $2.003-5.125$ & $<0.001$ \\
\hline Tumor size ( $>5$ vs $\leq 5 \mathrm{~cm}$ ) & 3.747 & $2.374-5.913$ & $<0.001$ & 3.949 & $2.531-6.161$ & $<0.001$ \\
\hline Capsule (poorly vs well) & 1.048 & $0.677-1.623$ & 0.832 & 1.119 & $0.737-1.697$ & 0.598 \\
\hline Liver cirrhosis (without/mild vs moderate/severe) & 8.984 & $5.443-14.827$ & $<0.001$ & 9.798 & $5.955-16.119$ & $<0.001$ \\
\hline TNM stage (III vs I/II) & 13.612 & $7.240-25.589$ & $<0.001$ & 12.074 & $6.480-22.500$ & $<0.001$ \\
\hline Edmondson's grade (III/IV vs I/II) & 1.471 & $0.932-2.321$ & 0.098 & 1.377 & $0.895-2.120$ & 0.146 \\
\hline Child-Pugh class (B vs A) & 1.056 & $0.625-1.785$ & 0.839 & 1.125 & $0.689-1.838$ & 0.638 \\
\hline Vascular invasion (present vs absent) & 22.957 & $11.683-45.112$ & $<0.001$ & 19.039 & $10.248-35.372$ & $<0.001$ \\
\hline AFP (>400 vs $\leq 400 \mathrm{ng} / \mathrm{ml})$ & 0.983 & $0.634-1.523$ & 0.939 & 0.983 & $0.648-1.492$ & 0.936 \\
\hline HBsAg (positive vs negative) & 0.887 & $0.457-1.721$ & 0.722 & 0.919 & $0.489-1.729$ & 0.793 \\
\hline ECM1 (positive vs negative) & 3.066 & $1.691-5.562$ & $<0.001$ & 2.294 & $1.360-3.872$ & 0.002 \\
\hline
\end{tabular}

$P$ value was generated by univariate analyses using the Cox regression model. $P<0.05$ was considered as statistically significant 
Table 5 Multivariate survival analysis of OS and DFS in 120 patients with HCC

\begin{tabular}{|c|c|c|c|c|c|c|}
\hline \multirow[t]{2}{*}{ Characteristics } & \multicolumn{3}{|l|}{ OS } & \multicolumn{3}{|l|}{ DFS } \\
\hline & $\mathrm{HR}$ & $95 \% \mathrm{Cl}$ & $P$ & $\mathrm{HR}$ & $95 \% \mathrm{Cl}$ & $P$ \\
\hline Nodule (multiple vs single) & 2.482 & $1.417-4.348$ & 0.001 & 1.961 & $1.140-3.373$ & 0.015 \\
\hline Tumor size ( $>5$ vs $\leq 5 \mathrm{~cm}$ ) & 2.009 & $1.144-3.529$ & 0.015 & 2.529 & $1.464-4.369$ & 0.001 \\
\hline Liver cirrhosis (without/mild vs moderate/severe) & 6.879 & $2.964-15.968$ & $<0.001$ & 6.703 & $3.078-14.598$ & $<0.001$ \\
\hline Vascular invasion (present vs absent) & 4.291 & $1.848-9.960$ & 0.001 & 3.430 & $1.563-7.527$ & 0.002 \\
\hline ECM1 (positive vs negative) & 4.481 & $2.021-9.934$ & $<0.001$ & 3.289 & $1.601-6.758$ & 0.001 \\
\hline
\end{tabular}

$P$ value was generated by multivariate survival analysis performed for all parameters that were significant in the univariate analyses using the Cox regression model. $P<0.05$ was considered as statistically significant

As shown in Fig. 6, compared with the control group, after the up-regulated expression of ECM1, the number of invading Bel-7402 cells was significantly increased $(89.3 \pm$ 2.5 cells/well vs $28.7 \pm 2.5$ cells/well). ( $t=29.524, P<0.01)$.

\section{Discussion}

Cytoplasmic ECM1 expression seems preferentially expressed in metastatic epithelial tumors, and it has been observed in breast cancer, thyroid carcinoma, laryngeal carcinoma, etc. [17, 18, 20, 21]. To date, little is known about the association between ECM1 expression and clinicopathological characteristics and prognosis of HCC. In the present study, HCC patients with positive ECM1 expression had significantly poor survival rates, especially in the subgroups of patients with invasive phenotypes, such as those with advanced TNM stage and vascular invasion. Using Cox multivariate regression analysis, ECM1 expression was an independent prognostic factor for OS and DFS of HCC patients. Therefore, it was proposed that the presence of ECM1 would be efficient for the prediction of HCC metastasis and prognosis.

Although many studies have reported that ECM1 affected not only the malignant cellular proliferation, but the cancer cell migration and invasion, the exact mechanisms by which ECM1 promoted tumor progression remained unclear. HCC is one of the most common malignant tumors in China, but few patients have chance to radical excision, postoperative recurrence rate is extremely high, and migration and invasion are the main factors of recurrence of HCC. In the migration of tumor involving a variety of regulatory mechanism, EMT is one of the important mechanisms, which was first discovered at key transition steps during embryogenesis and was the critical event that mediated tumor metastasis [23]. EMT refers to the epithelial cells in certain cases to the phenomenon of mesenchymal cells; the main features for the loss of epithelial phenotype and the get of mesenchymal phenotype result in heightened cell motility and invasiveness through diminished cell-cell and cell-matrix adhesion, reorganization of the cytoskeleton, and remodeling of the ECM [24-26]. Vimentin has been recognized as a very important marker for EMT, and its overexpression has been strongly associated with metastatic phenotype and poor prognosis. More and more evidence suggest that EMT plays an extremely important role during the process of the spread of cancer of $\mathrm{HCC}$ $[27,28]$.
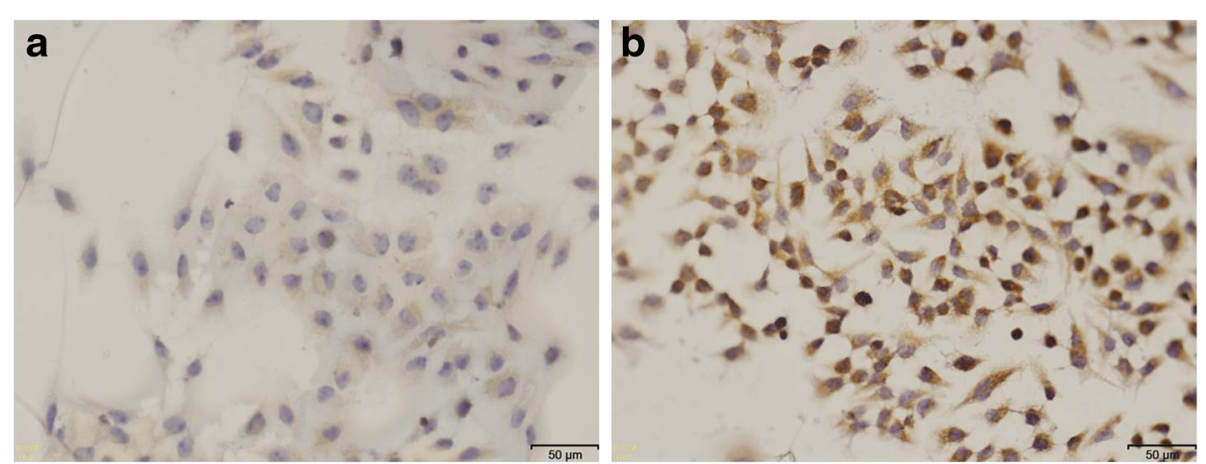

Fig. 3 a Representative pictures of ECM1 staining in Bel-7402 cells, ECM1 mainly expressed in the cytoplasm of cells. b Representative pictures of ECM1 staining in ECM1-Bel-7402 cells. The ECM1 level of Bel-7402 cells was significantly increased detected by immunohistochemical staining. Original magnification at $\times 200$ 


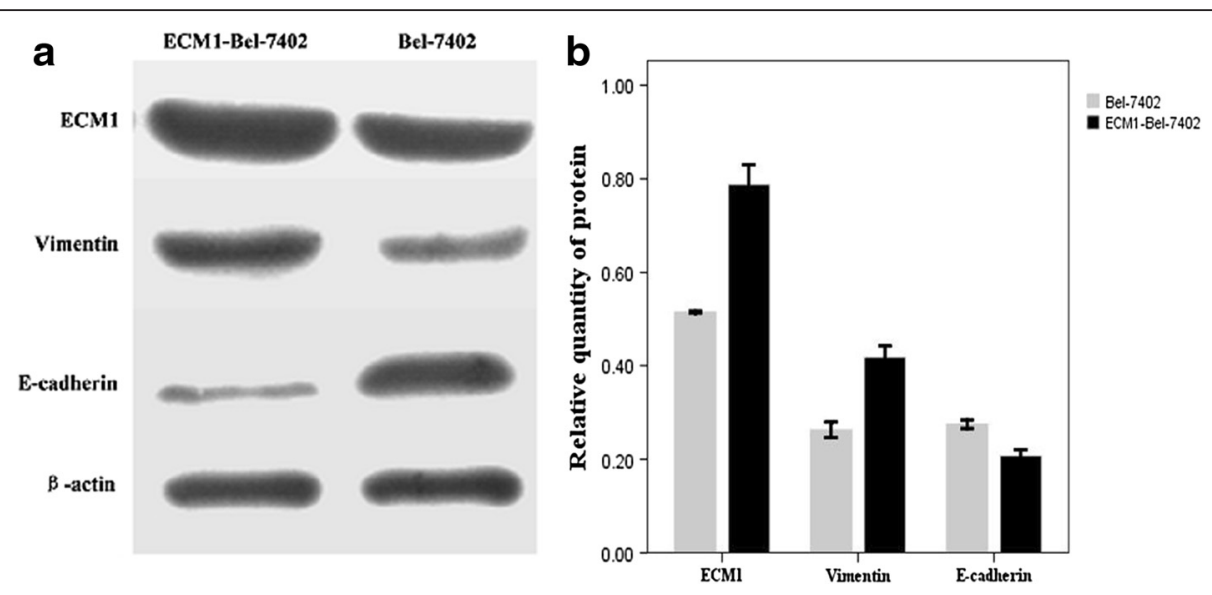

Fig. 4 a Changes of ECM1 and EMT-related protein (E-cadherin and Vimentin) expression in Bel-7402 cells were detected by Western blot after ECM1 transfection. The increased expression of ECM1 could lead to the up-regulated expression of Vimentin protein and down-regulated expression of E-cadherin protein in Bel-7402 cells. $\mathbf{b}$ The relative quantity of three protein expressed levels in cells with significant difference (ECM1: $t=12.909$, $P<0.01$; Vimentin; $t=10.564, P<0.01$; E-cadherin: $t=-8.558, P=0.002$ ). Relative quantity of three protein expressed levels in cells. Data are mean $\pm S D$ of three replicates. $(P<0.05)$

Primary studies have reported that ECM1 may promote EMT progression and increases the CSS phenotypes through the stabilization of $\beta$-catenin protein by MUC1 [29]. But whether ECM1 can promote migration of HCC through the induction of EMT is unclear. This experiment which mainly studies ECM1 in the role of
EMT-induced liver cancer metastasis further clarifies the important effect of the migration in liver cancer invasion. Our previous study suggests that ECM1 is overexpressed in both HCC cells and tissues compared with their benign counterparts [19]. On this basis, this research transfects ECM1 into Bel-7402 HCC cell line,

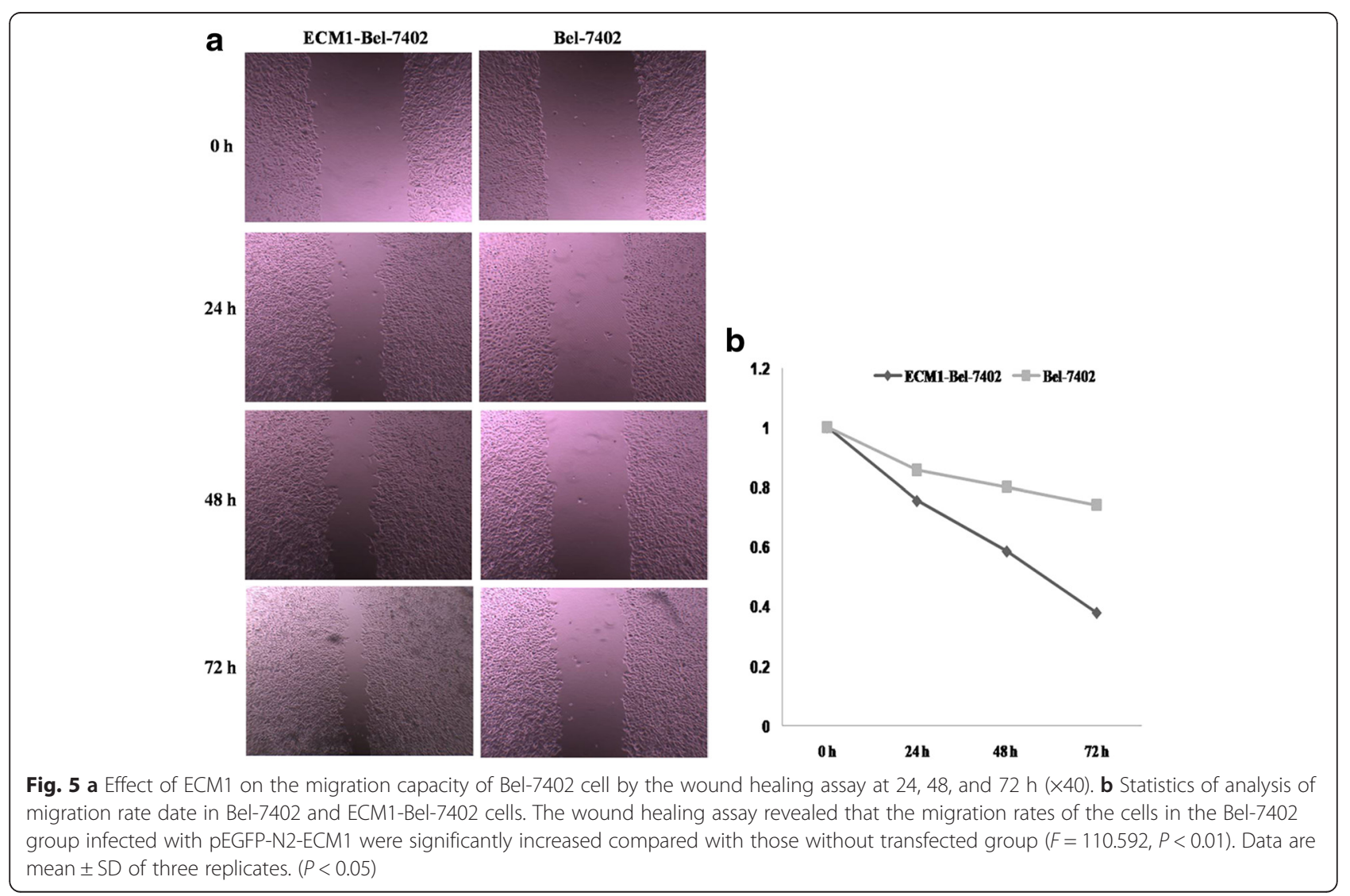




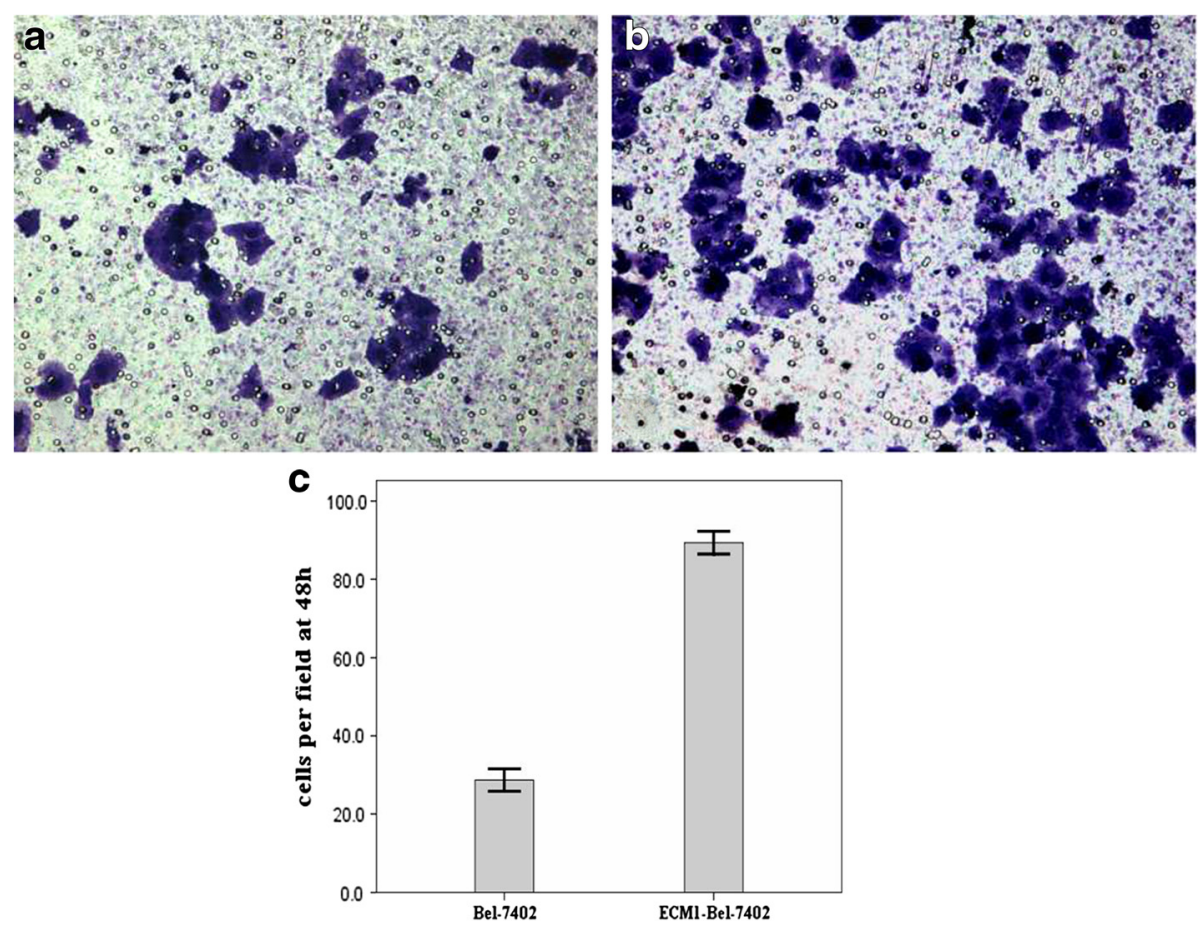

Fig. $\mathbf{6}$ a, b Effect of ECM1 on the invasion capacity of Bel-7402 and ECM1-Bel-7402 cells by invasion assay (×200). c Statistics of analysis of cells per field in Bel-7402 and ECM1-Bel-7402 cells at $48 \mathrm{~h}$. Compared with the control group, after the up-regulated expression of ECM1, the number of invading Bel-7402 cells was significantly increased ( $89.3 \pm 2.5$ cells/well vs $28.7 \pm 2.5$ cells/well) $(t=29.524, P<0.01)$. Data are mean \pm SD of three replicates $(P<0.05)$

induced by exogenous ECM1 expression. In this study, we found that the up-regulated expression of ECM1 was able to induce EMT. The expression of E-cadherin significantly declined, and Vimentin was significantly increased, which are very important markers for EMT, suggesting that ECM1-Bel-7402 cells can be induced to the occurrence of EMT. The tumor progression and metastasis-inducing capability in vitro of HCC cell line were also significantly enhanced, which is consistent with previous findings in this study.

\section{Conclusions}

Comprehensive above research results, our study indicated that the expression of ECM1 in HCC tissues was significantly associated with invasive phenotypes of HCC. ECM1 is a novel diagnostic marker for predicting the prognosis of HCC patients, although further study with a larger sample size was needed to confirm the current findings. As a secretory glycoprotein, detection of serum ECM1 level in HCC patients should be considered. We also found that ECM1 could induce liver cancer cell migration by EMT, this may provide a new train of thought for $\mathrm{HCC}$ effective diagnosis and treatment. But the intrinsic mechanism of ECM1 promoting the migration of tumor is very complex, and the induction of EMT may only be one of these links; therefore, other mechanisms of ECM1 by which in the process of HCC cell migration still need to be further discussed.

\section{Additional files}

Additional file 1: The changes of the expression of ECM1 in Bel-7402 cells effect some protenin levels, and the ability of migration and invasive potential of Bel-7402 cells. (XLSX 40 kb)

Additional file 2: One hundred twenty patient's clinical characteristics and the complete follow-up data. (XLS $36 \mathrm{~kb}$ )

\section{Abbreviations}

AFP, a-fetoprotein; DAB, 3,3-diaminobenzidine tetrahydrochloride; DFS, disease-free survival; DMEM, Dulbecco's modified Eagle's medium; ECM1, extracellular matrix protein 1; EMT, epithelia-mesenchymal transition; HbsAg, hepatitis B surface antigen; HCC, hepatocellular carcinoma; OS, overall survival; PBS, phosphate-buffered saline; TNM, tumor-node-metastasis

\section{Acknowledgements}

None.

\section{Funding}

This study was supported by the National Natural Science Foundation of China (No. 81172364), Anhui Provincial Natural Science Foundation of Institution of Higher Education (No. KJ2011A171).

\section{Availability of data and materials}

The datasets supporting the conclusions of this article are available of the repository of Ethics Committee for Clinical Research of AnHui Provincial Hospital. 


\section{Authors' contributions}

LJS designed the study, did the immumohistochemistry staining, and made the follow-up. $\mathrm{CH}$ performed the experiments and data analysis, participated in the cell culture, and guided the assay. JWD wrote the manuscript and also contributed to the major funding support. All authors read and approved the final manuscript.

\section{Competing interests}

The authors declare that they have no competing interests.

\section{Consent for publication}

A copy of the written consent is available for review by the Editor-in-Chief of this journal.

\section{Ethics approval and consent to participate}

This study is approved by the institutional Ethics Committee and Reviewed Board of AnHui Provincial Hospital. All study participants, or their legal guardian, provided informed written consent prior to study enrollment.

Received: 15 April 2016 Accepted: 20 July 2016

Published online: 27 July 2016

\section{References}

1. Jemal A, Bray F, Center MM, Ferlay J, Ward E, Forman D. Global cancer statistics. CA Cancer J Clin. 2011:61:69-90.

2. Crissien AM, Frenette $C$. Current management of hepatocellular carcinoma. Gastroenterol Hepatol (N Y). 2014;10:153-61.

3. O'Connor JW, Gomez EW. Biomechanics of TGFbeta-induced epithelialmesenchymal transition: implications for fibrosis and cancer. Clin Transl Med. 2014;3:23.

4. Thiery JP. Epithelial-mesenchymal transitions in tumour progression. Nat Rev Cancer. 2002:2:442-54.

5. Cano A, Perez-Moreno MA, Rodrigo I, Locascio A, Blanco MJ, del Barrio MG, et al. The transcription factor snail controls epithelial-mesenchymal transitions by repressing E-cadherin expression. Nat Cell Biol. 2000;2:76-83.

6. Bhalerao J, Tylzanowski P, Filie JD, Kozak CA, Merregaert J. Molecular cloning, characterization, and genetic mapping of the cDNA coding for a novel secretory protein of mouse. Demonstration of alternative splicing in skin and cartilage. J Biol Chem. 1995;270:16385-94.

7. Mathieu E, Meheus L, Raymackers J, Merregaert J. Characterization of the osteogenic stromal cell line MN7: identification of secreted MN7 proteins using two-dimensional polyacrylamide gel electrophoresis, western blotting, and microsequencing. J Bone Miner Res. 1994:9:903-13.

8. Mongiat M, Fu J, Oldershaw R, Greenhalgh R, Gown AM, lozzo RV. Perlecan protein core interacts with extracellular matrix protein 1 (ECM1), a glycoprotein involved in bone formation and angiogenesis. J Biol Chem. 2003:278:17491-9.

9. Hamada T, McLean WH, Ramsay M, Ashton GH, Nanda A, Jenkins T, et al. Lipoid proteinosis maps to $1 \mathrm{q} 21$ and is caused by mutations in the extracellular matrix protein 1 gene (ECM1). Hum Mol Genet. 2002;11:833-40.

10. Han Z, Ni J, Smits P, Underhill CB, Xie B, Chen Y, et al. Extracellular matrix protein 1 (ECM1) has angiogenic properties and is expressed by breast tumor cells. FASEB J. 2001;15:988-94.

11. Liu W, Xu W, Yang X, Lian S. A novel missense mutation of the ECM1 gene in a Chinese patient with lipoid proteinosis. Clin Exp Dermatol. 2011;37:28-30.

12. Sercu S, Zhang M, Oyama N, Hansen U, Ghalbzouri AE, Jun G, et al. Interaction of extracellular matrix protein 1 with extracellular matrix components: ECM1 is a basement membrane protein of the skin. J Invest Dermatol. 2008;128:1397-408.

13. Fujimoto N, Terlizzi J, Aho S, Brittingham R, Fertala A, Oyama N, et al. Extracellular matrix protein 1 inhibits the activity of matrix metalloproteinase 9 through high-affinity protein/protein interactions. Exp Dermatol. 2006;15:300-7.

14. Lupo I, Cefalu AB, Bongiorno MR, Daniele O, Valenti V, Noto D, et al. A novel mutation of the extracellular matrix protein 1 gene (ECM1) in a patient with lipoid proteinosis (Urbach-Wiethe disease) from Sicily. Br J Dermatol. 2005; 153:1019-22.

15. Hamada T, Wessagowit V, South AP, Ashton GH, Chan I, Oyama N, et al. Extracellular matrix protein 1 gene (ECM1) mutations in lipoid proteinosis and genotype-phenotype correlation. J Invest Dermatol. 2003;120:345-50.
16. Lal G, Contreras PG, Kulak M, Woodfield G, Bair T, Domann FE, et al. Human melanoma cells over-express extracellular matrix 1 (ECM1) which is regulated by TFAP2C. PLoS One. 2013;8:e73953.

17. Gu M, Guan J, Zhao L, Ni K, Li X, Han Z. Correlation of ECM1 expression level with the pathogenesis and metastasis of laryngeal carcinoma. Int J Clin Exp Pathol. 2013;6:1132-7.

18. Xiong GP, Zhang JX, Gu SP, Wu YB, Liu JF. Overexpression of ECM1 contributes to migration and invasion in cholangiocarcinoma cell. Neoplasma. 2012;59:409-15.

19. Chen $H$, Jia WD, Li JS, Wang W, Xu GL, Ma JL, et al. Extracellular matrix protein 1, a novel prognostic factor, is associated with metastatic potential of hepatocellular carcinoma. Med Oncol. 2011;28 Suppl 1:S318-25.

20. Lal G, Hashimi S, Smith BJ, Lynch CF, Zhang L, Robinson RA, et al. Extracellular matrix 1 (ECM1) expression is a novel prognostic marker for poor long-term survival in breast cancer: a hospital-based cohort study in lowa. Ann Surg Oncol. 2009;16:2280-7.

21. Lal G, Padmanabha L, Nicholson R, Smith BJ, Zhang L, Howe JR, et al. ECM1 expression in thyroid tumors - a comparison of real-time RT-PCR and IHC. J Surg Res. 2008;149:62-8.

22. Wang L, Yu J, Ni J, Xu XM, Wang J, Ning H, et al. Extracellular matrix protein 1 (ECM1) is over-expressed in malignant epithelial tumors. Cancer Lett. 2003:200:57-67.

23. Guarino M. Epithelial-mesenchymal transition and tumour invasion. Int J Biochem Cell Biol. 2007:39:2153-60.

24. Thompson EW, Newgreen DF, Tarin D. Carcinoma invasion and metastasis: a role for epithelial-mesenchymal transition? Cancer Res. 2005:65:5991-5. discussion 5995

25. Lamouille S, Xu J, Derynck R. Molecular mechanisms of epithelialmesenchymal transition. Nat Rev Mol Cell Biol. 2014;15:178-96.

26. Jung $H Y$, Fattet $L$, Yang J. Molecular pathways: linking tumor microenvironment to epithelial-mesenchymal transition in metastasis. Clin Cancer Res. 2014;21:962-8.

27. Chen J, Liu WB, Jia WD, Xu GL, Ma JL, Huang M, et al. Overexpression of mortalin in hepatocellular carcinoma and its relationship with angiogenesis and epithelial to mesenchymal transition. Int J Oncol. 2014;44:247-55.

28. van Zijl F, Zulehner G, Petz M, Schneller D, Kornauth C, Hau M, et al. Epithelial-mesenchymal transition in hepatocellular carcinoma. Future Oncol. 2009;5:1169-79.

29. Lee KM, Nam K, Oh S, Lim J, Kim RK, Shim D, et al. ECM1 regulates tumor metastasis and CSC-like property through stabilization of beta-catenin. Oncogene. 2015;34:6055-65.

\section{Submit your next manuscript to BioMed Central and we will help you at every step:}

- We accept pre-submission inquiries

- Our selector tool helps you to find the most relevant journal

- We provide round the clock customer support

- Convenient online submission

- Thorough peer review

- Inclusion in PubMed and all major indexing services

- Maximum visibility for your research

Submit your manuscript at www.biomedcentral.com/submit 